\title{
ESTENOSE ARTERIAL NOS TRANSPLANTES RENAIS
}

\section{ARTERIAL STENOSIS AFTER RENAL TRANSPLANTATION}

\author{
Warley Dias Siqueira Mendes,ACBC-RJ'1 ; Luís Felipe da Silva,TCBC-RJ'2 ; Gaudencio Espinosa,TCBC-RJ33 \\ André Luiz Fernandes ${ }^{4}$; Roberto Furtado ${ }^{5}$; Renato Gonçalves ${ }^{6}$
}

\begin{abstract}
RESUMO: Objetivo: Relacionar a influência dos dois tipos de anastomoses arteriais empregadas (término-terminal e término-lateral), da idade do receptor, do rim de doador vivo ou cadáver e do uso de remendo aórtico ("patch") quanto à presença ou não de estenose da artéria renal e, avaliar o tratamento destas estenoses. Método: Estudo retrospectivo de 278 pacientes submetidos a transplante renal no Hospital Universitário Clementino Fraga Filho (HUCFF), de maio de 1989 a maio de 2001. Resultados: Não se mostrou relação entre as variáveis estudadas com a presença ou não de estenose da artéria renal. A estenose da artéria renal foi detectada em oito casos, que foram tratados, com sucesso, mediante angioplastia transluminal percutânea (ATP), com implante primário de "stent" (n = 7) ou sem implante de "stent" ( $\mathrm{n}=1)$. Conclusões: As variáveis estudadas não influenciaram no aparecimento da estenose da artéria renal e o tratamento endovascular foi efetivo na correção destas lesões estenóticas (Rev. Col. Bras. Cir. 2005; 32(5): 237-243).
\end{abstract}

Descritores: Transplante de rim; Obstrução da artéria renal; Angioplastia com balão.

\section{INTRODUÇÃO}

O transplante renal, realizado como tratamento dos pacientes com insuficiência renal crônica, vem ocupando destaque cada vez maior devido aos benefícios que podem ser promovidos pela cirurgia de transplante, quando indicada e conduzida corretamente.

A insuficiência renal crônica é responsável por restringir o paciente à máquina de diálise durante várias horas por semana, aumentando as chances de adquirir infecções e contaminações, além de prejudicar sua vida social. Esses fatos podem ser solucionados por meio do transplante renal com bons resultados. Entretanto, o transplante renal pode evoluir com complicações clínicas, decorrentes do uso de drogas imunossupressoras, ou urológicas e vasculares. O objetivo deste estudo é avaliar a influência dos dois tipos de anastomoses arteriais empregadas (término-terminal e término-lateral), da idade do receptor, do enxerto renal de doador vivo ou cadáver e do uso de remendo aórtico quanto à presença ou não de estenose da artéria renal, num período de 12 anos, em um único centro e pela mesma equipe cirúrgica, e avaliar o tratamento das estenoses encontradas.

\section{MÉTODO}

Foram analisados, retrospectivamente, 278 prontuários de pacientes submetidos à cirurgia de transplante renal, por uma mesma equipe cirúrgica, num período de 12 anos, de maio de 1989 a maio de 2001, no Hospital Universitário Clementino Fraga Filho (HUCFF) da Universidade Federal do Rio de Janeiro. Os pacientes foram avaliados quanto à idade, ao tipo de doador (vivo ou cadáver), ao tipo de anastomose vascular realizada (término-terminal ou término-lateral) e ao uso de remendo aórtico, e foram discutidas as influências destas variáveis na incidência de estenose da artéria renal.

Os tipos de anastomoses com a artéria renal estão relacionados com o sítio receptor, ou seja, com as artérias receptoras. A rotina do Serviço de Cirurgia Vascular do HUCFF é realizar preferencialmente anastomose do tipo término-terminal, reservando-se as anastomoses término-laterais para os casos em que a artéria hipogástrica está ocluída ou apresenta doença aterosclerótica grave.

Todos os pacientes estudados foram avaliados préoperatoriamente pelo Serviço de Nefrologia, através da avaliação da compatibilidade sanguínea (ABO e prova cruzada), das funções cardíaca, pulmonar e hepática, além da avaliação da sorologia para os vírus da hepatite "B", "C" e HIV.

Os pacientes foram submetidos à anestesia geral e bloqueio raquidiano e operados em conjunto pelos Serviços de Cirurgia Vascular e Urologia. A técnica cirúrgica de implante renal, de rotina, consistiu em abordagem retroperitoneal, acesso aos vasos ilíacos, anastomose arterial preferencialmente término-terminal entre a artéria do enxerto renal e a artéria hipogástrica, utilizando fio de polipropileno 6-0 em pontos separados.

1. Mestre em Medicina, área de concentração Cirurgia Geral, setor Cirurgia Vascular, pela Faculdade de Medicina da UFRJ.

2. Chefe do Departamento de Cirurgia da Faculdade de Medicina da UFRJ; Professor Adjunto do Departamento de Cirurgia da Faculdade de Medicina da UFRJ - lotado no Serviço de Cirurgia Vascular do HUCFF.

3. Professor Adjunto do Departamento de Cirurgia da UFRJ - lotado no Serviço de Cirurgia Vascular do HUCFF.

4. Chefe do Serviço de Cirurgia Vascular do HUCFF; Professor Assistente do Departamento de Cirurgia da Faculdade de Medicina da UFRJ.

5. Médico do Serviço de Cirurgia Vascular do HUCFF.

6. Coordenador do Transplante Renal no HUCFF.

Recebido em: 21/02/2005

Aceito para publicação em: 29/07/2005

Conflito de interesse: nenhum

Fonte de financiamento: nenhuma

Trabalho realizado no Departamento de Cirurgia da Faculdade de Medicina e Serviço de Cirurgia Vascular do Hospital Universitário Clementino Fraga Filho - (HUCFF) Universidade Federal do Rio de Janeiro. 
Tabela 1 - Relação entre os tipos de anastomoses e a idade do receptor (doador vivo).

\begin{tabular}{lcc}
\hline Anastomose & $\mathbf{5 4 0}$ anos de idade & $\mathbf{> 4 0}$ anos de idade \\
\hline Término-terminal & 129 & 58 \\
Término-lateral & 3 & 12 \\
Total & 132 & 70 \\
\hline
\end{tabular}

Fischer $=0,0003$

Tabela 2 - Relação entre os tipos de anastomoses e a idade do receptor (doador cadáver).

\begin{tabular}{lcc}
\hline Anastomose & $\mathbf{4 4 0}$ anos de idade & $\mathbf{> 4 0}$ anos de idade \\
\hline Término-terminal & 33 & 35 \\
Término-lateral & 2 & 6 \\
Total & 35 & 41 \\
\hline
\end{tabular}

Fischer $=0,2751$

Os casos foram avaliados desde o primeiro transplante realizado no HUCFF, em 16 de maio de 1989, até maio de 2001, para que todos os pacientes estudados apresentassem mais de dois anos de evolução. Quanto à idade, os pacientes estudados foram divididos em dois grupos: os com idade até 40 anos e os com idade acima de 40 anos, considerando que os receptores com idade acima de 40 anos apresentam maior incidência de doença arteriosclerótica.

Os pacientes pós-transplante, com diminuição importante da função renal e hipertensão arterial sistêmica, sem melhora clínico-medicamentosa e laudo ultra-sonográfico sugestivo de estenose da artéria renal, foram submetidos a estudo através de angiografia seletiva com contraste iodado não iônico. Os pacientes considerados com estenose, para o estudo, foram os que mostraram estenose hemodinamicamente significativa $(>60 \%)$ à arteriografia.

$\mathrm{O}$ tratamento empregado nos pacientes com estenose hemodinamicamente significativa foi o tratamento endovascular pela técnica de angioplastia transluminal percutânea (ATP) com o implante primário de "stent" ou sem o implante de "stent". Os tipos de "stent" utilizados foram o Herculink $^{\circledR}$ (Guidant, CA, EUA) ou Multi-Link Ultra ${ }^{\circledR}$ (Guidant, CA, EUA), que variaram de tamanho, de 5x13mm a 7x18mm. O acompanhamento pós-procedimento foi realizado clinicamente (com a avaliação da pressão arterial e função renal) e ultrasonograficamente, com "eco-color-Doppler".

A análise estatística empregada foi a Prova Exata de Fischer, visando comparar a relação entre duas variáveis categóricas distintas. Foi utilizado o "software Minitab 12.1 for Windows" para a realização dos cálculos. O nível de significância empregado foi de $5 \%$ ou 0,05 . Assim, quando o resultado do teste foi menor que 0,05 o resultado foi considerado significativo.

\section{RESULTADO}

A idade dos receptores variou de oito a 66 anos, com média de 37 anos. Cento e setenta e cinco pacientes eram do
Tabela 3 - Relação entre os tipos de doadores e a presença ou não de estenose.

\begin{tabular}{lcc}
\hline Doador & Estenose presente & Estenose ausente \\
\hline Vivo & 7 & 195 \\
Cadáver & 1 & 75 \\
Total & 8 & 270 \\
\hline
\end{tabular}

Fischer $=0,4533$

Tabela 4 - Relação entre os tipos de anastomoses e a presença ou não de estenose.

\begin{tabular}{lcc}
\hline Anastomose & Estenose presente & Estenose ausente \\
\hline Término-terminal & 8 & 247 \\
Término-lateral & 0 & 23 \\
Total & 8 & 270 \\
\hline
\end{tabular}

Fischer $=1,0000$

sexo masculino e 103 pacientes eram do sexo feminino. Foram realizadas 255 anastomoses do tipo término-terminal, com a artéria hipogástrica, e 23 anastomoses do tipo término-lateral, com as artérias ilíacas comum $(n=4)$ ou externa $(n=19)$

Dos 278 pacientes operados, 202 foram receptores de doadores vivos (73\%) e 76 de doadores cadáveres (27\%). Analisados os pacientes receptores de enxerto renal de doador vivo $(n=202)$, pôde-se observar que existe relação altamente significativa (Fischer $=0,0003$ ) entre o tipo de anastomose empregada e a idade do receptor, observando-se uma maior incidência de anastomoses do tipo término-terminal $(n=129)$ nos pacientes com idade até 40 anos $(n=167)$. A do tipo término-lateral, embora menos freqüente que a términoterminal, quando realizada, ocorreu preferencialmente nos pacientes acima de 40 anos $(n=111)$ (Tabela 1$)$.

Nos pacientes receptores de doador cadáver $(n=$ 76), não existiu relação entre o tipo de anastomose e a idade do receptor (Tabela 2 ).

Foram encontrados sete casos de estenose anastomótica (Figura 1) e um caso na artéria hipogástrica (Figura 2). Os pacientes que foram receptores de doador vivo foram os que mais apresentaram estenose $(n=7)$. A análise estatística mostrou que não existiu relação entre o tipo de doador com a condição do paciente ter ou não estenose (Tabela 3).

Quando se analisam os dados relacionando os tipos de anastomoses com a presença de estenose, a totalidade das estenoses ocorreu nas anastomoses do tipo término-terminal. Desta forma, todos os casos ocorreram nos pacientes que tiveram anastomose com a artéria hipogástrica. A análise estatística mostrou que não existiu relação entre a artéria receptora e, conseqüentemente, o tipo de anastomose escolhida, com a presença ou não de estenose (Tabela 4$)$.

Nos casos com estenose $(\mathrm{n}=8)$, pôde-se observar que cinco $(62 \%)$ ocorreram em pacientes com idade até 40 anos. Foi analisada a idade do receptor e relacionada com a presença ou não de estenose. Constata-se que não existiu relação estatística (Fischer $=1,0000)$ entre a idade do receptor e a presença ou não de estenose (Tabela 5). 

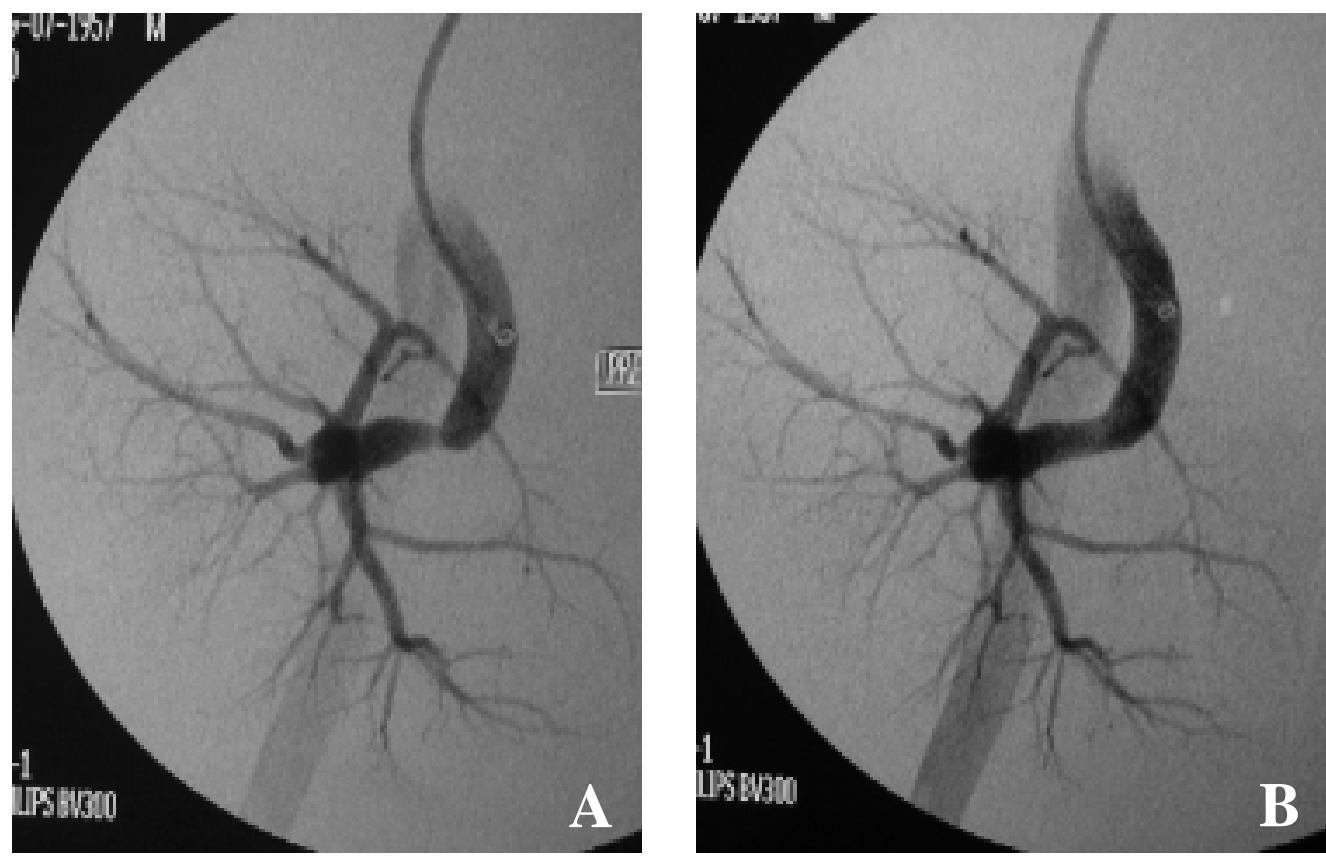

Figura 1 - Estudo angiográfico mostrando: (A) estenose hemodinamicamente significativa (>70\%) no local da anastomose entre a artéria renal e a artéria hipogástrica (seta); (B) bom resultado após a angioplastia com implante de stent.

Não foi observada estenose nas anastomoses que utilizaram remendo arterial, ou seja, segmento da parede da aorta do doador cadáver $(n=4)$. A análise estatística mostrou que não existiu relação entre o uso de remendo e a presença ou não de estenose (Tabela 6).

Em todos os pacientes em que foi diagnosticada estenose hemodinamicamente significativa $(n=8)$, foi observada hipertensão arterial sistêmica, apesar do uso de três ou mais medicações associadas, com média de sistólica de $170 \pm 30$ mmHg e média de diastólica de $105 \pm 15 \mathrm{mmHg}$. Foi observada, também, retenção nitrogenada (média de creatinina de 2,10 \pm 15 $\mathrm{mg} / \mathrm{dl})$. No estudo com "eco-color-Doppler" no local da estenose da artéria renal, quando hemodinamicamente significativa, observou-se pico de velocidade sistólica máxima duas vezes maior que no segmento antes do local da estenose, enquanto que, após a estenose encontrou-se pulso alterado ("parvus et tardus") e tempo de aceleração > 100 ms.
Constatada a estenose, foi feito o tratamento endovascular em todos os pacientes $(n=8)$, com bom resultado angiográfico em $100 \%$ dos casos. Em sete pacientes, foi necessário utilizar "stent" e, em um paciente, foi realizada apenas a angioplastia pela técnica de dois balões insuflados ao mesmo tempo, na bifurcação da artéria renal (Figura 3). Em um caso $(12,5 \%)$, foi observado, no estudo com "eco-colorDoppler" após 23 meses de tratamento, aumento da velocidade sistólica no local do "stent" e, embora o estudo angiográfico não tenha confirmado estenose, foi realizada nova angioplastia com balão de maior diâmetro para aumentar a seção do "stent" implantado previamente na artéria hipogástrica, reduzindo a desproporção de diâmetro entre a artéria do enxerto e a artéria hipogástrica.

Após o tratamento endovascular, todos os pacientes foram avaliados clínica e ultra-sonograficamente e foi observada melhora da pressão arterial, com o uso de até duas
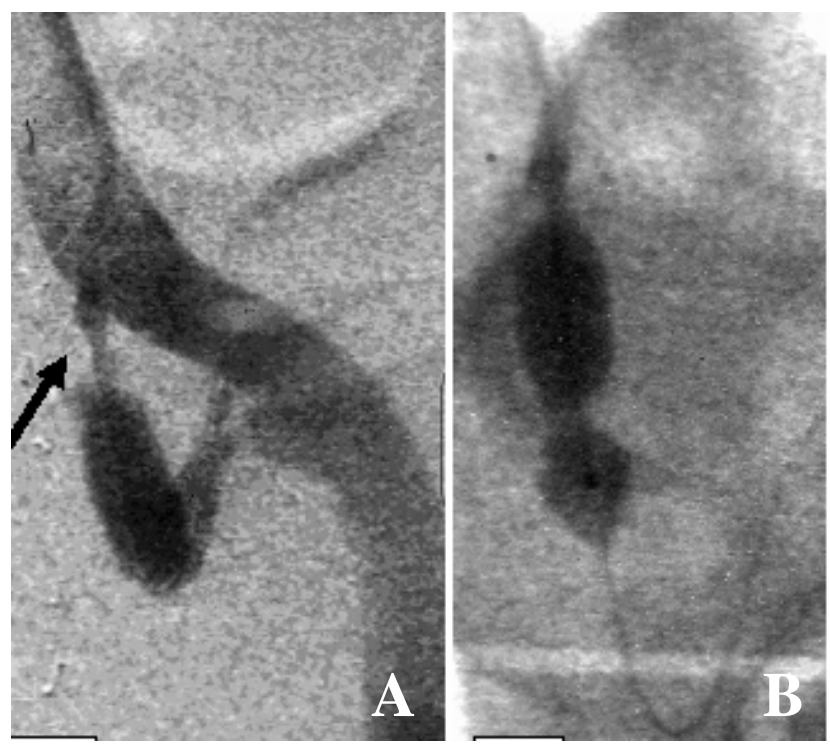

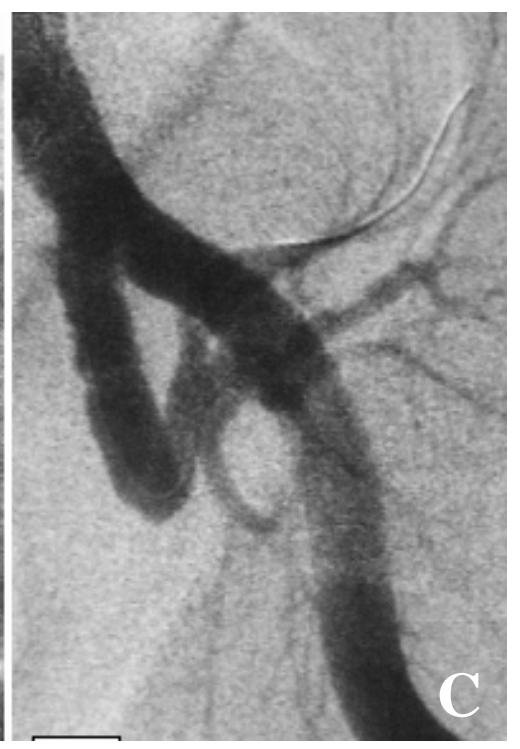

Figura 2 - (A) Angiografia seletiva mostrando estenose crítica (90\%) na origem da artéria hipogástrica (seta); (B) Angioplastia; (C) Resultado angiográfico satisfatório, após angioplastia com implante de stent. 
Tabela 5 - Relação entre a idade do receptor e a presença ou não de estenose.

\begin{tabular}{lcc}
\hline Idade do receptor & Estenose presente & Estenose ausente \\
\hline$\leq 40$ anos & 5 & 162 \\
$>40$ anos & 3 & 108 \\
Total & 8 & 270 \\
\hline
\end{tabular}

Fischer $=1,0000$

medicações associadas, com média de sistólica de $120 \pm 20$ mmHg e média de diastólica de $75 \pm 15 \mathrm{mmHg}$. Foi observada redução dos níveis das escórias nitrogenadas (média de creatinina de $1,40 \pm 10 \mathrm{mg} / \mathrm{dl}$ ). No estudo com "eco-colorDoppler" da artéria renal, observou-se normalização do pulso e da velocidade sistólica máxima na artéria renal.

\section{DISCUSSÃo}

As complicações vasculares são pouco freqüentes, nos transplantes renais. Permanecem, entretanto, como uma das maiores causas de morbidade, ocasionalmente resultando em disfunção do enxerto renal, retirada do enxerto ou morte do receptor ${ }^{1,2}$. As mais freqüentes são: estenose ou trombose da artéria do enxerto renal, fístula artério-venosa e trombose da veia renal. A estenose da artéria renal é a mais freqüente e ocorre em 1 a $15 \%$ dos pacientes transplanta$\operatorname{dos}^{3-6}$. No presente estudo, a estenose da artéria do enxerto renal ocorreu em oito casos $(2,88 \%)$, coincidindo com os relatos mais recentes da literatura mundial, que têm mostrado taxa de 1,5 a $7 \%{ }^{7}$.

Lacombe $^{8}$, em 1975, relatou um estudo realizado em 306 transplantes renais, no qual encontrou estenose da artéria renal em 38 casos e um índice de estenose de $12,4 \%$. Relatou também que a maior incidência de estenose ocorreu nos transplantes de doador cadáver. No presente estudo, observou-se que, dos 278 transplantes, oito casos apresentaram estenose e, somente um caso foi de doador cadáver. Durante a análise
Tabela 6 - Relação entre o uso de remendo de aorta na anastomose e a presença ou não de estenose.

\begin{tabular}{lcc}
\hline Anastomose & Estenose presente & Estenose ausente \\
\hline Com remendo & 0 & 4 \\
Sem remendo & 8 & 266 \\
Total & 8 & 270 \\
\hline
\end{tabular}

Fischer $=1,0000$

estatística, porém, verificou-se que não existiu relação entre o tipo de doador e a condição do paciente ter ou não estenose da artéria renal. A tendência para um menor número de estenoses, quando de doador cadáver, pode vir a ser atribuída ao uso mais freqüente de remendo aórtico.

As causas de estenose da artéria renal são: sutura inapropriada por falha técnica, lesão intimal durante a perfusão do enxerto ou durante a realização do implante, comprimento excessivo da artéria renal e torção ou tensão no local da sutu$\mathrm{ra}^{1,4-7}$. Aterosclerose e fibrose no local da anastomose também são causas de estenose da artéria renal e ocorrem geralmente, em um período mais tardio após o transplante ${ }^{9}$.

As estenoses podem ser classificadas em proximal à anastomose (devido à doença aterosclerótica na artéria receptora), no local da anastomose (local mais freqüente de estenose), ou distal ao local da anastomose (na artéria renal doada $)^{1,7}$. A estenose no local da anastomose pode ser conseqüente à falha técnica e/ou fibrose pós-operatória. A etiologia da estenose distal ao local da anastomose é pouco clara, mas pode ser relacionada a dano mecânico ou imunológico ${ }^{1,7}$. No presente estudo, foram encontrados sete casos de estenose anastomótica (por provável hiperplasia miointimal) e um caso de estenose na artéria hipogástrica, por provável progressão de doença aterosclerótica.

A etiologia da hipertensão arterial após transplante renal é múltipla e inclui muitas condições, tais como: rejeição do enxerto, toxicidade das drogas imunossupressoras, recorrência da doença renal original, doença dos rins nativos,
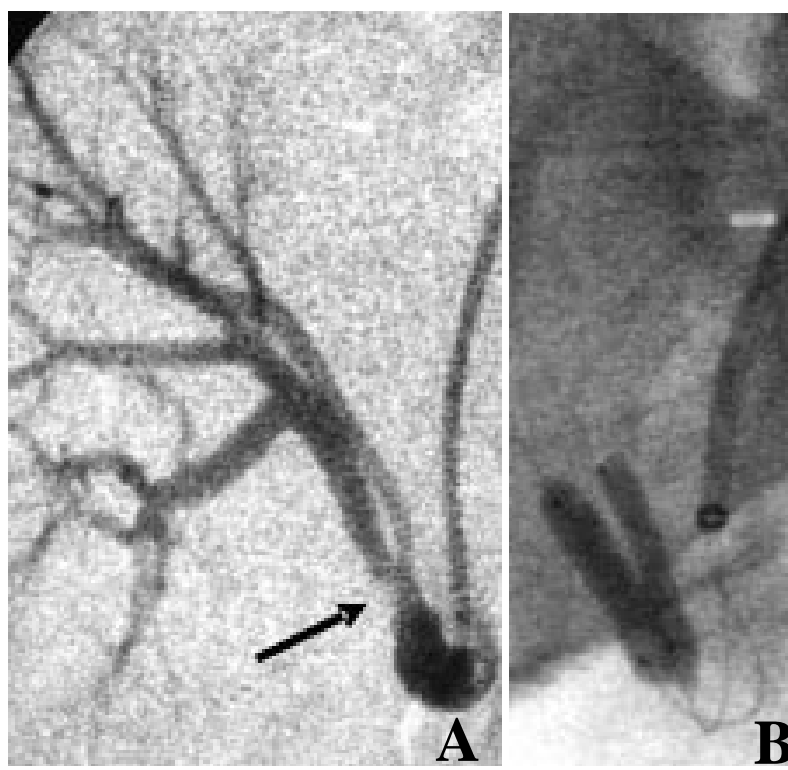

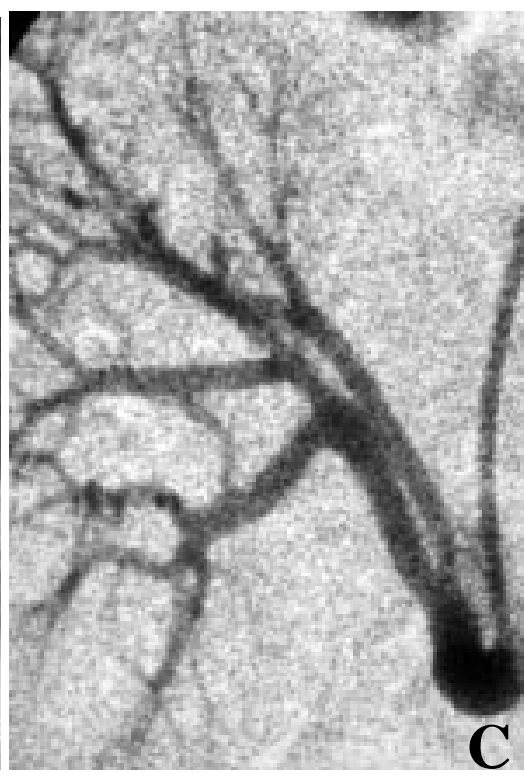

Figura 3 - (A) Angiografia seletiva mostrando estenose hemodinamicamente significativa (>60\%) no local da anastomose entre a artéria renal e a artéria hipogástrica (seta), próximo a bifurcação renal; (B) Angioplastia com dois balões insuflados ao mesmo tempo; (C) Resultado angiográfico satisfatório. 
hipertensão essencial e estenose da artéria renal ${ }^{1,6,7,10-13}$. Destas condições, a estenose arterial é responsável por hipertensão em $10 \%$ dos transplantes e representa causa potencialmente curável ${ }^{7,12,14}$. No presente estudo, a estenose arterial foi responsável por hipertensão em 2,88\% dos transplantes realizados.

Os achados clínicos que sugerem estenose da artéria renal são: hipertensão arterial grave, refratária a tratamento, sopro audível no sítio do enxerto, e hipertensão associada a inexplicável disfunção progressiva do enxerto ${ }^{1,4-6,15}$. A presença de hipertensão em receptores de transplante renal é achado clínico em 50-60\% dos casos, em longo prazo ${ }^{7,10}$. Dickerman et $a l .{ }^{11}$ relatam que a incidência de hipertensão varia de 13 a $80 \%$ dos casos.

Fontaine et al..$^{12}$ referem que a incidência pode alcançar até $85 \%$ dos transplantes renais em crianças. No presente estudo, todos os casos $(n=8)$ com estenose significativa hemodinamicamente $(>60 \%)$ apresentaram diminuição progressiva da função renal e hipertensão, apesar do uso de três ou mais medicações associadas.

O estudo com "eco-color-Doppler" da fossa ilíaca onde se encontra o enxerto é o exame de escolha para os receptores com disfunção do enxerto ${ }^{1,9,16}$. O pico de velocidade arterial elevado no "eco-color-Doppler" sugere, com acurácia de $87 \%$, fluxo vascular comprometido ${ }^{9,16}$. Sanz et al. ${ }^{1}$ relatam que a incidência de resultados falso-negativos ou falso-positivos torna necessária a realização de angiografia quando se suspeita de estenose.

A angiografia, exame considerado "padrão ouro" para o diagnóstico definitivo de estenose da artéria renal, é indicada para confirmar a lesão identificada na ultra-sonografia e planejar a conduta terapêutica ${ }^{6,7,9,16}$. No presente estudo, todos os casos $(n=8)$ com diminuição da função renal, hipertensão arterial refratária e com resultado ao "eco-color-Doppler" sugestivo de estenose hemodinamicamente significativa (>60\%) foram submetidos a estudo angiográfico.

Disfunção do enxerto renal de etiologia vascular é geralmente secundária à estenose da artéria renal transplantada. Entretanto, níveis de creatinina sérica elevados e hipertensão também podem estar presentes nos pacientes com estenose da artéria ilíaca proximal ao sítio do implante do enxerto. Estas lesões estenóticas estão localizadas na artéria ilíaca comum ou externa e são mais freqüentemente atribuídas à aterosclerose $^{16}$.

Humar et al. ${ }^{16}$ relatam um caso de disfunção de enxerto renal pós-transplante, conseqüente à estenose da artéria ilíaca externa, que foi tratada com implante de "stent". A estenose se desenvolveu proximal ao local de anastomose do enxerto, provavelmente secundária ao clampeamento vascular no momento do transplante. A estenose da artéria ilíaca externa, proximal ao local da anastomose, pode não só levar à disfunção do enxerto como também à síndrome isquêmica do membro inferior homolateral. Atualmente, a maioria dos centros médicos opta por realizar o implante renal na artéria ilíaca comum ou externa com técnica de anastomose término-lateral, por considerarem mais rápido e acreditarem que a artéria hipogástrica tem maior prevalência de doença aterosclerótica. Logo, a incidência de estenose nesses pacientes seria menor quando comparada aos pacientes com técnica de anastomose término-terminal na artéria hipogástrica ${ }^{2,4,17}$. No presente estudo, todos os casos de estenose $(n=8)$ ocorreram com a técnica de anastomose término-terminal, sendo um caso na origem da artéria hipogástrica, em decorrência de provável progressão de doença aterosclerótica.

Sutherland et al. ${ }^{4}$ realizaram estudo retrospectivo de 377 pacientes, nos quais em 185 foram realizadas anastomoses com a artéria hipogástrica e em 192 com a artéria ilíaca comum ou externa. Como resultado, 12 de 185 (6,5\%) e 13 de 192 (6,8\%) tiveram estenose na artéria renal transplantada, concluindo que não existe diferença na incidência de estenose, seja por anastomose término-terminal ou término-lateral. Dentre os pacientes com anastomose término-terminal, a incidência de estenose foi significativamente maior quando a endarterectomia da artéria hipogástrica foi requerida, oito de 12 casos.

Neste estudo, somente as anastomoses com a artéria hipogástrica apresentaram estenose $(n=8)$. Embora todos os casos de estenose tenham ocorrido com anastomose términoterminal na artéria hipogástrica, durante a análise estatística verificou-se não existir relação entre o tipo de anastomose escolhida com a presença ou não de estenose, o que pode ser conseqüente à pequena amostra de casos com anastomose término-lateral $(\mathrm{n}=23)$.

Rijksen et al.$^{18}$ sugerem que uma disparidade entre o diâmetro do vaso doador e do receptor em anastomose término-terminal é um fator contribuinte para o desenvolvimento de estenose. Höhnke et al. ${ }^{2}$ relataram que, na sua instituição, optam por realizar de primeira escolha a anastomose com a artéria ilíaca externa por considerarem não haver problemas técnicos com incongruência do diâmetro do vaso e em caso de retransplante, este pode ser realizado mais facilmente.

Embora a abordagem da artéria ilíaca comum ou externa seja mais fácil e rápida em comparação à artéria hipogástrica, que exige dissecção mais cuidadosa e ligadura de seus ramos, no HUCFF dá-se preferência pela artéria hipogástrica, considerando que a sua utilização preserva a artéria ilíaca comum ou externa para a necessidade de retransplante. Logo, não havendo necessidade de se interromper a circulação do membro inferior homolateral ao transplante, pode-se evitar as complicações inerentes ao manuseio da artéria ilíaca comum ou externa. Com relação à incompatibilidade de diâmetro do vaso, relatado por outros autores, isto tem sido superado com dissecção da artéria hipogástrica até sua porção distal, que apresenta menor diâmetro, ou até um de seus ramos, que podem ser utilizados como sítio de anastomose com a artéria renal do enxerto ou com as artérias polares, usando a técnica término-terminal.

Embora neste estudo tenha sido levantada a hipótese de que as doenças degenerativas sejam mais freqüentes em pacientes com mais de 40 anos, a análise estatística não mostrou existir relação entre a idade do receptor e a presença ou não de estenose. Apesar disto, quando o doador era vivo e se relacionou a idade do receptor com o tipo de anastomose, observou-se que a anastomose término-lateral foi mais utilizada em pacientes acima de 40 anos. A anastomose términoterminal foi mais utilizada nos pacientes até 40 anos, devido ao uso mais freqüente de artérias hipogástricas, sem doença 
aterosclerótica, nos mais jovens (= 40 anos). A análise estatística mostrou relação altamente significativa entre o tipo de anastomose e a idade do receptor, nos doadores vivos.

$\mathrm{O}$ tratamento de pacientes com estenose da artéria renal consiste em três modalidades: (1) clínico, no controle da hipertensão arterial; (2) ATP, como tratamento minimamente invasivo, e (3) cirurgia de revascularização ${ }^{18}$.

ATP apresenta cura ou melhora em $76 \%$ dos casos com descontinuação de pelo menos duas medicações antihipertensivas e, em alguns pacientes já em diálise, consegue recuperar a função renal ${ }^{7}$. Apesar de segura e eficaz, a ATP pode apresentar complicações em $10 \%$ dos $\operatorname{casos}^{7,17}$. No presente estudo, todos os pacientes $(n=8)$ submetidos a tratamento endovascular apresentaram bons resultados clínicos, com melhora da pressão arterial e da função renal. As dosagens de creatinina destes pacientes retornaram aos valores considerados normais para um paciente transplantado renal, ou seja, valores no limite máximo da normalidade ou levemente aumentados.

No HUCFF, sete casos de estenose arterial hemodinamicamente significativa $(>60 \%)$ foram tratados mediante angioplastia com implante primário de "stent", considerando que as possíveis complicações em nova intervenção no rim transplantado podem ser catastróficas, uma vez que tem a função de rim único no receptor. Em um caso que apresentava enxerto com artéria dupla, em cano de espingarda, foi realizada apenas ATP pela técnica de dois balões insuflados ao mesmo tempo. Optou-se por não utilizar "stent" pelo risco de oclusão da artéria remanescente.

Apresentando excelentes taxas de sucesso e menos complicações quando comparada à cirurgia, a ATP é hoje considerada método de escolha inicial no tratamento de estenose da artéria renal ${ }^{7,17}$. Recorrência de estenose da artéria renal após ATP pode ocorrer em 10 a 33\% dos casos. Entretanto, a ATP pode ser repetida e a cirurgia de revascularização ainda pode ser realizada, se necessário ${ }^{1,19,20}$. No presente estudo, não houve recorrência da estenose na artéria renal transplantada.

Bruno et al. ${ }^{21}$ relataram recentemente que o risco de reestenose após ATP, nas estenoses da artéria renal pós-transplante, pode ser prevenido realizando-se ATP associada ao uso de "stent". Guzmán-Rodríguez et al. ${ }^{22}$ relataram três casos tratados com sucesso mediante ATP com implante de "stent". No presente estudo, sete casos de estenose foram tratados com ATP e implante primário de "stent" balão-expansível.

Técnicas com o objetivo de evitar estenose durante o procedimento de implante renal devem ser utilizadas. Nos casos em que o rim doado seja um cadáver, este pode ser retirado em bloco com segmento da aorta, que poderá ser utilizado como remendo ao redor do orifício da artéria renal, e no qual será realizada a anastomose com a artéria receptora ${ }^{10}$. Este tipo de variação técnica tem sido utilizada mais recentemente, no HUCFF, quando há doença aterosclerótica grave da artéria hipogástrica, optando-se por realizar anastomose com a artéria ilíaca comum ou externa.

Todos os pacientes deste estudo, submetidos a tratamento de estenose da artéria renal, são acompanhados clinicamente por métodos que avaliam a função renal, por "ecocolor-Doppler" e por cintilografia renal com isótopos, além dos exames padrões de sangue e urina. $\mathrm{O}$ acompanhamento destes pacientes se torna importante tanto para se avaliar reincidência de estenose da artéria renal quanto para se diagnosticar qualquer outra doença, que deverá ser tratada e, ainda, salvaguardar as funções do rim transplantado ${ }^{23}$.

O presente estudo sugere que a estenose da artéria renal, após transplante renal, é uma variável independente e que o tipo de anastomose empregada, a idade do receptor, o tipo de doador (vivo ou cadáver) e o uso ou não de remendo aórtico não influenciam no seu aparecimento. O tratamento endovascular das estenoses da artéria renal pós-transplante mostrou ser efetivo no tratamento das estenoses arteriais que afetam o enxerto renal.

\begin{abstract}
Background: Our goal is to relate the type of anastomosis (end-to-end or end-to-side), the age of recipient patient, the type of renal graft used (live or cadaver donor) and the aortic patch usage to the development of renal artery stenosis, evaluating its treatment. Data were statistically analyzed using Fischer's Test. Methods: This is a retrospective study of 278 patients, submitted to renal implant surgery at the Clementino Fraga Filho University Hospital, from May, 1989 to May, 2001. Results: There was no demonstrable relation between the studied variables and the presence of stenosis. Renal artery stenosis was detected in eight cases, which were successfully treated through percutaneous transluminal angioplasty, with primary stent implant $(n=7)$ or without stent implant $(n=1)$. Conclusion: The analyzed variables didn't influence the development of renal artery stenosis. Endovascular treatment was effective for this pathology.
\end{abstract}

Key Words: Kidney transplantation; Renal artery obstruction; Angioplasty, balloon.

\section{REFERÊNCIAS}

1. del Valle Sanz Y, Lorente Ramos RM, Berrocal Frutos T, et al. Complicaciones vasculares en el transplante renal pediátrico: diagnóstico ecográfico. An Esp Pediatr. 1999; 50(3):263-8.

2. Droupy $S$, Eschwège $P$, Blanchet $P$, et al. Recipient arterial repairs during renal transplantation. Transplant Proc. 2002; 34(3): 814 .
3. Höhnke C, Abendroth D, Schleibner, S. et al. Vascular complications in 1200 kidney transplantations. Transplant Proc. 1987; 19:3691-2.

4. Sutherland RS, Spees EK, Jones JW, et al. Renal artery stenosis after renal transplantation: the impact of the hypogastric artery anastomosis. J Urol. 1993; 149(5): 980-5.

5. Halvorsen CE, Hartmann A, Jenssen T, et al. Salvage of a renal graft by percutaneous transluminal angioplasty of the occluding transplant artery. Nephrol Dial Transplant. 1999; 14(9):2231-3. 
6. Sert S, Dalgic A, Sindel S, et al. Renal artery reconstruction in transplant kidney. Case report. Int Urol Nephrol. 1998; 30(5):639-43.

7. Rengel M, Gomes Da Silva G, Inchaustegui L, et al. Renal artery stenosis after kidney transplantation: diagnostic and therapeutic approach. Kidney Int. 1998;54(Suppl.68): S99-S106.

8. Lacombe M. Arterial stenosis complicating renal allotransplantation in man: a study of 38 cases. Ann Surg. 1975; 181(3):283-8.

9. Krumme B, Pisarski P, Blum U, et al. Unusual Cause of Early Graft Dysfunction after Kidney Transplantation. Am J Nephrol. 1998; 18(3):237- 9.

10. Tilney NL, Rocha A, Strom TB, et al. Renal artery stenosis in transplant patients. Ann Surg. 1984; 199(4):454-60.

11. Dickerman RM, Peters PC, Hull AR, et al. Surgical correction of posttransplant renovascular hypertension. Ann Surg. 1980; 192(5):639-44.

12. Fontaine E, Beurton D, Barthelemy Y, et al. Renal artery stenosis following pediatric renal transplantation. Transplant Proc. 1994; 26(1):293-4.

13. Agroyannis B, Fourtounas C, Mourikis D, et al. Management of claudication and hypertension by stent implantation in a renal transplant recipient. J Hum Hypertens. 1998; 12(6):417-8.

14. De Meyer M, Pirson Y, Dautrebande J, et al. Treatment of renal graft artery stenosis. Comparison between surgical bypass and percutaneous transluminal angioplasty. Transplantation. 1989; 47(5):784-8.

15. Benoit G, Moukarzel M, Hiesse C, et al. Transplant renal artery stenosis: experience and comparative results between surgery and angioplasty. Transplant Int. 1990; 3(3):137-40.

16. Humar A, Grubbs B, Zapzalka D, et al. Isolated iliac artery stenosis as a cause of kidney graft dysfunction post-transplant. Clin Transplant. 1998; 12(5):406-8.
17. Juvenois A, Ghysels M, Galle C, et al. Successful revascularization for acute renal allograft thrombosis after 32 hours of ischaemia. Nephrol Dial Transplant. 1999; 14(1):199201.

18. Rijksen JF, Koolen, MI, Walaszewski JE, et al. Vascular complications in 400 consecutive renal allotransplants. J Cardiovasc Surg. 1982; 23(2)91-8.

19. Martinez AG, Novick AC, Hayes JM. Surgical treatment of renal artery stenosis after failed percutaneous transluminal angioplasty. J Urol. 1990; 144(5):1094-6.

20. Martin LG, Rundback JH, Sacks D, et al. Quality improvement guidelines for angiography, angioplasty, and stent placement in the diagnosis and treatment of renal artery stenosis in adults. J Vasc Interv Radiol. 2002; 13(11):1069-83.

21. Bruno S, Remuzzi G, Ruggenenti P. Transplant renal artery stenosis. J Am Soc Nephrol. 2004; 15(1):134-41.

22. Guzmán-Rodríguez JH, Plata-Muñoz JJ, Mancilla E, et al. Estenosis arterial renal posterior a trasplante: tratamiento con angioplastia transluminal percutánea y colocación de endoprótesis luminal metálica expandible. Rev Invest Clin. 2003; 55:297-304.

23. Gruntzig A, Kuhlmann U, Vetter W, et al. Treatment of renovascular hypertension with percutaneous transluminal dilatation of a renal-artery stenosis. Lancet. 1978; 1(8068):801-2.

Endereço para correspondência:

Warley Dias Siqueira Mendes

Rua: Barão de Itapagipe, 445/306.

Tijuca - Rio de Janeiro - RJ

CEP: 20261-000 